\title{
Cation-permeable vacuolar ion channels in the moss Physcomitrella patens: a patch-clamp study
}

\author{
Mateusz Koselski • Kazimierz Trebacz • \\ Halina Dziubinska
}

Received: 25 February 2013/ Accepted: 15 May 2013/Published online: 29 May 2013

(c) The Author(s) 2013. This article is published with open access at Springerlink.com

\begin{abstract}
Patch-clamp studies carried out on the tonoplast of the moss Physcomitrella patens point to existence of two types of cation-selective ion channels: slowly activated (SV channels), and fast-activated potassium-selective channels. Slowly and instantaneously saturating currents were observed in the whole-vacuole recordings made in the symmetrical $\mathrm{KCl}$ concentration and in the presence of $\mathrm{Ca}^{2+}$ on both sides of the tonoplast. The reversal potential obtained at the $\mathrm{KCl}$ gradient $(10 \mathrm{mM}$ on the cytoplasmic side and $100 \mathrm{mM}$ in the vacuole lumen) was close to the reversal potential for $\mathrm{K}^{+}\left(E_{\mathrm{K}}\right)$, indicating $\mathrm{K}^{+}$selectivity. Recordings in cytoplasm-out patches revealed two distinct channel populations differing in conductance: $91.6 \pm 0.9$ $\mathrm{pS}(n=14)$ at $-80 \mathrm{mV}$ and $44.7 \pm 0.7 \mathrm{pS}(n=14)$ at $+80 \mathrm{mV}$. When $\mathrm{NaCl}$ was used instead of $\mathrm{KCl}$, clear slow vacuolar SV channel activity was observed both in wholevacuole and cytoplasm-out membrane patches. There were no instantaneously saturating currents, which points to impermeability of fast-activated potassium channels to $\mathrm{Na}^{+}$and $\mathrm{K}^{+}$selectivity. In the symmetrical concentration of $\mathrm{NaCl}$ on both sides of the tonoplast, currents have been measured exclusively at positive voltages indicating $\mathrm{Na}^{+}$ influx to the vacuole. Recordings with different concentrations of cytoplasmic and vacuolar $\mathrm{Ca}^{2+}$ revealed that $\mathrm{SV}$ channel activity was regulated by both cytoplasmic and vacuolar calcium. While cytoplasmic $\mathrm{Ca}^{2+}$ activated SV channels, vacuolar $\mathrm{Ca}^{2+}$ inhibited their activity. Dependence of fast-activated potassium channels on the cytoplasmic $\mathrm{Ca}^{2+}$ was also determined. These channels were
\end{abstract}

M. Koselski $(\bowtie) \cdot$ K. Trebacz $\cdot$ H. Dziubinska Department of Biophysics, Institute of Biology and Biochemistry, Maria Curie-Skłodowska University, Akademicka 19, 20-033 Lublin, Poland e-mail: mateusz.koselski@poczta.umcs.lublin.pl active even without $\mathrm{Ca}^{2+}$ ( 2 mM EGTA in the cytosol and the vacuole lumen), although their open probability significantly increased at $0.1 \mu \mathrm{M} \mathrm{Ca}{ }^{2+}$ on the cytoplasmic side. Apart from monovalent cations $\left(\mathrm{K}^{+}\right.$and $\left.\mathrm{Na}^{+}\right), \mathrm{SV}$ channels were permeable to divalent cations $\left(\mathrm{Ca}^{2+}\right.$ and $\left.\mathrm{Mg}^{2+}\right)$. Both monovalent and divalent cations passed through the channels in the same direction-from the cytoplasm to the vacuole. The identity of the vacuolar ion channels in Physcomitrella and ion channels already characterised in different plants is discussed.

Keywords Physcomitrella Potassium channels . SV channels - Tonoplast
Abbreviations
$\mathrm{SV}$
VK
$\mathrm{FV}$
Slowly activating vacuolar channel
$\mathrm{E}_{\mathrm{K} / \mathrm{Na} / \mathrm{Ca} / \mathrm{Mg}}$ Vacuolar $\mathrm{K}^{+}$channel
$\left[\mathrm{Ca}^{2+}\right]_{\text {cyt }}$ Fast activating vacuolar channel
$\left[\mathrm{Ca}^{2+}\right]_{\text {vac }}$ Reversal potential for potassium/sodium/ calcium/magnesium
EGTA Cytoplasmic $\mathrm{Ca}^{2+}$ concentration
TPC Vacuolar $\mathrm{Ca}^{2+}$ concentration
TPK Ethylene glycol tetraacetic acid Two-pore channel Two-pore $\mathrm{K}^{+}$channel

\section{Introduction}

The central vacuole is the largest intracellular organelle in plant cells, which stores many ions and takes part in crucial physiological processes including intracellular signalling. Different types of cation- and anion-selective channels were characterised in plant vacuoles using the patch-clamp 
technique (Allen and Sanders 1997; Pottosin and Schönknecht 2007; Hedrich and Marten 2011; Hedrich 2012).

The slow vacuolar channel SV is one of the best characterised vacuolar channels (Pottosin and Schönknecht 2007; Hedrich and Marten 2011; Gutla et al. 2012; Hedrich 2012). SV channels are relatively non-selective cation channels. Their permeability to $\mathrm{K}^{+}$and $\mathrm{Na}^{+}$is approximately equal and usually higher than that to divalent cations: $\mathrm{Ca}^{2+}$ and $\mathrm{Mg}^{2+}$. SV channels are usually activated by a high non-physiological cytoplasmic $\mathrm{Ca}^{2+}$ concentration, $\left[\mathrm{Ca}^{2+}\right]_{\text {cyt }}$ exceeding $10 \mu \mathrm{M}$ (Schulze et al. 2011). Currents passing through SV channels exhibit time-dependent saturation and rectification promoting cation transport from the cytosol to the vacuolar lumen. The membrane potential activating SV currents is shifted to positive values in respect to a physiological (negative) potential range. These two factors seem to limit the physiological role(s) of SV channels to osmoregulation and sequestration of toxic cations. On the other hand, multiple ways of SV channel regulation by factors that are usually lost during vacuole isolation for a patch-clamp study, like kinases/phosphatases, 14-3-3-proteins, polyamines, etc., make the question of their role in cell signalling open. Identification of the gene encoding the SV channel protein (Peiter et al. 2005) allowed quick progress in examination of SV channel operation (Isayenkov et al. 2010; Dadacz-Narloch et al. 2011; Schulze et al. 2011). Subtle structural differences in SV channels among different plants in connection with the multiple steps of their regulation cause significant differences in their kinetics, susceptibility to activating factors, and surface density (Rienmüller et al. 2010).

Potassium cations, most abundant in the vacuole, can also flow through two different vacuolar channels: highly selective potassium channels (VK) and fast-activated channels (FV). VK channels were originally found in guard cell vacuoles (Ward and Schroeder 1994) and then in other plant tissues (Pottosin et al. 2003). They are activated by $\left[\mathrm{Ca}^{2+}\right]_{\text {cyt }}$ in a micromolar range. VK channels are voltageindependent. In Arabidopsis, VK channels are encoded by TPKI-a tandem pore channel (Gobert et al. 2007).

FV channels are non-selective cation channels (Allen et al. 1998; Pottosin et al. 2003). In contrast to SV channels, they activate instantaneously. FV channels are active at a submicromolar $\mathrm{Ca}^{2+}$ concentration. Higher concentrations of these cations inhibit FV channels on both sides of the vacuolar membrane (Tikhonova et al. 1997). Such a great variety of vacuolar potassium channels indicates that the vacuole plays a crucial role in $\mathrm{K}^{+}$homeostasis.

The moss Physcomitrella patens is a model plant often used by molecular biologists and geneticists due to its highly efficient homologous recombination, allowing generation of knockout mutants (by means of gene targeting) and testing functions of selected genes. Physcomitrella is a well-known model for research of the impact of some environmental factors on physiological processes in plants. Up to now, the effects of salinity, drought and osmotic stress (Frank et al. 2005), nutritious element deficiency (Kroemer et al. 2004), and low and high temperature have been examined (Minami et al. 2005; Saidi et al. 2009).

The TPCl ortholog from Physcomitrella patens was expressed in Arabidopsis thaliana with silenced native TPC1 genes encoding SV channel proteins (Dadacz-Narloch et al. 2011). Clear SV channel activity was demonstrated in this heterologous system. However, up to now, there are no published electrophysiological data concerning vacuolar ion channels in Physcomitrella wild-type plants. We decided to fill this gap and examine ion channels of Physcomitrella in a native system-vacuoles isolated from the moss gametophyte.

\section{Materials and methods}

\section{Plant material}

The moss Physcomitrella patens was a kind gift from Prof. Dr. Ralf Reski (University of Freiburg, Germany). Moss gametophytes were cultivated in a growth chamber at $22{ }^{\circ} \mathrm{C}$ under a $16 / 8 \mathrm{~h}$ light/dark photoperiod with light intensity of $60 \mu \mathrm{mol} \mathrm{m}{ }^{-2} \mathrm{~s}^{-1}$ in Petri dishes containing solidified Knop medium (Reski and Abel 1985). Maintenance of the moss culture was achieved by monthly subculturing of young gametophytes into a fresh medium. The fast rate of growth and great abilities of vegetative reproduction resulted in formation of a small colony of a few young gametophytes from one gametophyte after 2-3 weeks.

\section{Vacuole isolation}

Vacuole isolation was carried out using a nonenzymatic method described by Trebacz and Schönknecht (2000). Before the experiments, the gametophyte leaves were plasmolysed in a medium containing $650 \mathrm{mM}$ sorbitol, $15 \mathrm{mM}$ HEPES/Tris, pH 7, and different ions, depending on the type of the experiment. After 20-30 min, the leaves were cut with a razor blade and transferred to the measuring chamber containing a medium with a slightly lower osmotic pressure than the plasmolysing solution. During deplasmolysis, a few protoplasts that were not destroyed by incision emerged in the cutting line from open cell walls. Reduction of the osmotic pressure of the medium to $300 \mathrm{mOsm} \mathrm{kg} \mathrm{kg}^{-1}$ resulted in rupture of the protoplasts and vacuole release. 
Patch-clamp experiments

Currents flowing either through the whole tonoplast ("whole-vacuole" configuration) or through a small patch of the tonoplast ("cytoplasm-out" configuration) were measured during the patch-clamp experiments. The micropipettes were made of borosilicate glass tubes with $1.5 \mathrm{~mm}$ outer diameter (Kimax-51, Kimble Products) pulled using a two-step puller PP-830 (Narishige, Tokyo, Japan) and firepolished by a microforge MF 200-2 (World Precision Instruments, Sarasota, FL, USA). $\mathrm{An} \mathrm{Ag} / \mathrm{AgCl}$ reference electrode with a ceramic porous bridge was immersed in the bath solution and filled with $100 \mathrm{mM} \mathrm{KCl}$. Liquid junction potentials were calculated using JPCalcW written by P.H. Barry (University of New South Wales, Sydney, Australia). Osmolality of all solutions used during the measurements was adjusted with sorbitol to $300 \mathrm{mOsm} \mathrm{kg} \mathrm{kg}^{-1}$ using a cryoscopic osmometer (Osmomat 030, Gonotec). Recordings were made using a patch-clamp amplifier EPC-10 (Heka Electronik) running under the Patchmaster software (Heka Elektronik). The sampling rate was $10 \mathrm{kHz}$ and filter frequency was $2 \mathrm{kHz}$. Statistical analysis, current/voltage characteristics (I/V), and current density/voltage characteristics (J/V) were elaborated using SigmaPlot 9.0 (Systat Software Inc.). Current and voltage signs followed the convention proposed by Bertl et al. (1992).

\section{Solution composition}

Basic solutions used to examine the activity of $\mathrm{K}^{+}$-permeable channels contained $100 \mathrm{mM} \mathrm{KCl}, 2 \mathrm{mM} \mathrm{CaCl}_{2}$, $15 \mathrm{mM} \mathrm{HEPES} /$ Tris, $\mathrm{pH} 7$ in the bath (cytosol) and $100 \mathrm{mM} \mathrm{KCl}, 2 \mathrm{mM} \mathrm{CaCl}_{2}, 15 \mathrm{mM}$ MES/Tris, pH 5.8 in the pipette (vacuole lumen). Solutions used to examine the activity of $\mathrm{Na}^{+}$-permeable channels were composed of $100 \mathrm{mM} \mathrm{NaCl}, 2 \mathrm{mM} \mathrm{CaCl}_{2}, 15 \mathrm{mM}$ HEPES/Tris, $\mathrm{pH} 7$ in the bath and $100 \mathrm{mM} \mathrm{NaCl}, 2 \mathrm{mM} \mathrm{CaCl} 2,15 \mathrm{mM}$ MES/ Tris, pH 5.8 in the pipette. Selectivity of $\mathrm{K}^{+}$- and $\mathrm{Na}^{+}$permeable channels was checked by changing solutions in the bath to $10 \mathrm{mM} \mathrm{KCl}, 2 \mathrm{mM} \mathrm{CaCl}, 15 \mathrm{mM}$ HEPES/ Tris, $\mathrm{pH} 7$ (in the case of $\mathrm{K}^{+}$-permeable channels) and $10 \mathrm{mM} \mathrm{NaCl}, 2 \mathrm{mM} \mathrm{CaCl} 2,15 \mathrm{mM}$ HEPES/Tris, $\mathrm{pH} 7$ (in the case of $\mathrm{Na}^{+}$-permeable channels). Dependence of the channel activity on $\mathrm{Ca}^{2+}$ was checked using different concentration of that ion. The concentration of free $\mathrm{Ca}^{2+}$ was determined using a Ca-EGTA Calculator v1.2 (http:// maxchelator.stanford.edu/CaEGTA-NIST.htm). Solutions used to study the activity of $\mathrm{Mg}^{2+}$-permeable channels consisted of $10 \mathrm{mM} \mathrm{MgCl} 2,15 \mathrm{mM}$ HEPES/Tris, $\mathrm{pH} 7$ in the bath and $100 \mathrm{mM} \mathrm{MgCl}_{2}, 15 \mathrm{mM}$ MES/Tris, $\mathrm{pH} 5.8$ in the pipette. Solutions used to study the activity of $\mathrm{Ca}^{2+}$. permeable channels consisted of $1 \mathrm{mM} \mathrm{CaCl}, 15 \mathrm{mM}$ HEPES/Tris, pH 7 in the bath and $10 \mathrm{mM} \mathrm{CaCl}_{2}, 15 \mathrm{mM}$
MES/Tris, pH 5.8 in the pipette. Exchange of the solutions in the measuring chamber was accomplished by a peristaltic pump (Ismatec ISM796B) before recording.

\section{Results}

We examined ion channels in $P$. patens in symmetrical (in the bath and in the pipette) solutions containing $100 \mathrm{mM}$ $\mathrm{KCl}$ and $2 \mathrm{mM} \mathrm{CaCl}_{2}$. These conditions favoured activation of SV channels in Conocephalum conicum - a bryophyte closely related to Physcomitrella (Trebacz and Schönknecht 2000).

The whole vacuole records in Physcomitrella (Fig. 1a, b) differed from typical SV. In addition to slowly activating currents at positive voltages, fast activating currents were recorded at both positive and negative tonoplast voltages. The density of the currents was higher at positive than at negative voltages (Fig. 1c). The tenfold decrease in the $\mathrm{K}^{+}$concentration to $10 \mathrm{mM}$ on the cytoplasmic side caused shift of the reversal potential close to $E_{\mathrm{K}}$ indicating $\mathrm{K}^{+}$selectivity. In addition, the $\mathrm{KCl}$ gradient caused a decrease in positive currents (Fig. 1b, c). A decrease in the $\mathrm{K}^{+}$concentration on the cytoplasmic side did not change negative currents, which could be carried by other than the SV channel type.

Application of $\mathrm{Na}^{+}$instead of $\mathrm{K}^{+}$in the bath and pipette solutions revealed that the fast-activated component of the currents disappeared leaving SV currents unchanged (Fig. 1d). Currents passing through SV channels decreased after a tenfold decrease in the $\mathrm{Na}^{+}$concentration to $10 \mathrm{mM}$ on the cytoplasmic side (Fig. 1e, g). In such conditions, relaxation currents (tail currents) were observed (Fig. 1f). The reversal potential for those currents was at positive voltages close to $E_{\mathrm{Na}}$. A positive shift of the reversal potential was also observed at $\mathrm{J}-\mathrm{V}$ curves calculated from the steady state currents (Fig. 1g). These results confirmed, on the one hand, nearly equal permeability of SV channels to $\mathrm{K}^{+}$and $\mathrm{Na}^{+}$and, on the other hand, impermeability of fast-activated channels to $\mathrm{Na}^{+}$, which points to $\mathrm{K}^{+}$selectivity of these channels.

The activity of single channels was recorded in isolated tonoplast patches in the cytoplasm-out configuration excised from vacuoles in whole-vacuole configuration. Recordings obtained in the symmetrical $\mathrm{K}^{+}$concentration (as in Fig. 1a) show the activity of the channels at both negative and positive voltages (Fig. 2a). The unitary conductance of the channels was higher at negative voltages $[91.6 \pm 0.9 \mathrm{pS}(n=14)$ at $-80 \mathrm{mV}]$ than at positive ones $[44.7 \pm 0.7 \mathrm{pS}(n=14)$ at $+80 \mathrm{mV}]$. The reason for the difference in conductance could be either the activity of two different types of channels or the multi-ion character of one channel allowing simultaneous conductance of more 

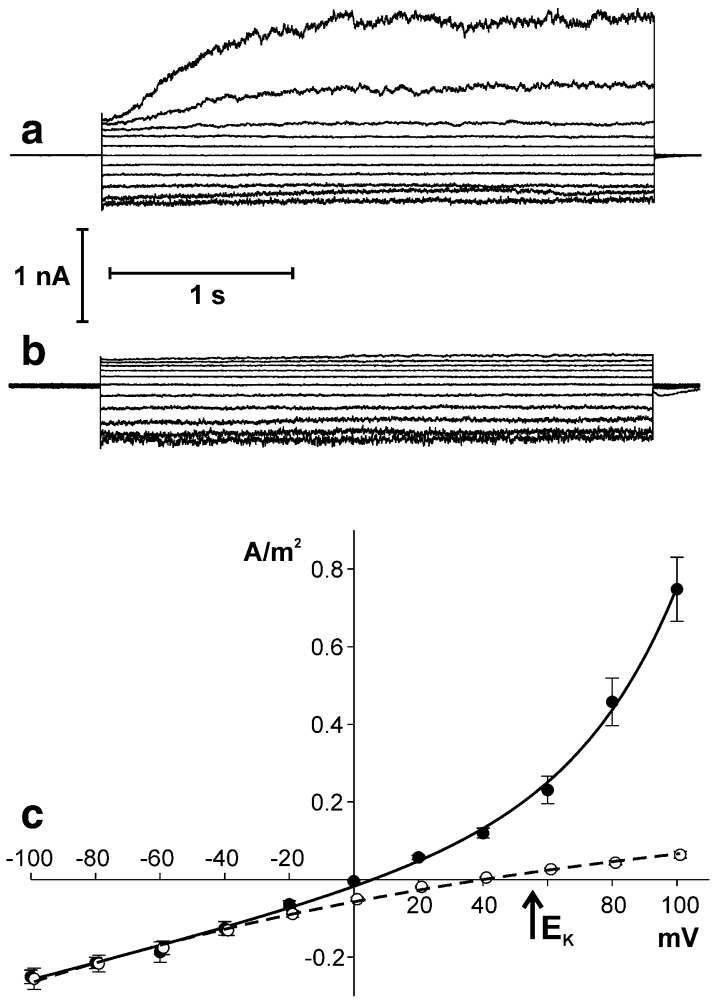

Fig. 1 Ion channel activity recorded in Physcomitrella patens vacuoles when the current was carried by $\mathrm{K}^{+}(\mathbf{a}-\mathbf{c})$ and $\mathrm{Na}^{+}(\mathbf{d}-\mathbf{g})$. a Whole-vacuole currents recorded at $100 \mathrm{mM} \mathrm{KCl}, 2 \mathrm{mM} \mathrm{CaCl}$, $15 \mathrm{mM}$ HEPES/Tris, $\mathrm{pH} 7$ in the medium and $100 \mathrm{mM} \mathrm{KCl}, 2 \mathrm{mM}$ $\mathrm{CaCl}_{2}, 15 \mathrm{mM}$ MES/Tris, pH 5.8 in the pipette. b Whole-vacuole currents recorded at $10 \mathrm{mM} \mathrm{KCl}, 2 \mathrm{mM} \mathrm{CaCl}_{2}, 15 \mathrm{mM}$ HEPES/Tris, $\mathrm{pH} 7$ in the medium and $100 \mathrm{mM} \mathrm{KCl}, 2 \mathrm{mM} \mathrm{CaCl}_{2}, 15 \mathrm{mM} \mathrm{MES/}$ Tris, $\mathrm{pH} 5.8$ in the pipette. c $\mathrm{J}-\mathrm{V}$ curves obtained in the same conditions as in $\mathbf{a}$ (solid line and closed circles, $n=6$ ) and $\mathbf{b}$ (dashed lines and open circles, $n=10$ ), respectively. d Whole-vacuole currents recorded at $100 \mathrm{mM} \mathrm{NaCl}, 2 \mathrm{mM} \mathrm{CaCl}_{2}, 15 \mathrm{mM}$ HEPES/ Tris, $\mathrm{pH} 7$ in the medium and $100 \mathrm{mM} \mathrm{NaCl}, 2 \mathrm{mM} \mathrm{CaCl}_{2}, 15 \mathrm{mM}$ MES/Tris, pH 5.8 in the pipette. e Whole-vacuole currents recorded at $10 \mathrm{mM} \mathrm{NaCl}, 2 \mathrm{mM} \mathrm{CaCl}_{2}, 15 \mathrm{mM}$ HEPES/Tris, $\mathrm{pH} 7$ in the medium

than one ion. SV channels in different plant vacuoles are reported to possess such characteristics. However, the open probability of these channels at negative voltages is very low. In contrast, in Physcomitrella the open probability at negative voltages was very high-it reached $0.946 \pm 0.005$ $(n=4)$ at $-80 \mathrm{mV}$ (in conditions as in Fig. 2a). These results indicate once more that at negative voltages currents passing through channels different from SV have been recorded.

In order to separate SV currents from the others, we replaced $\mathrm{K}^{+}$with $\mathrm{Na}^{+}$on both sides of the tonoplast. In such conditions, we recorded channel activity only at positive voltages with characteristic time dependence of SV channels (Fig. 2b). Conductance of this channel was smaller than that of the channel examined in the
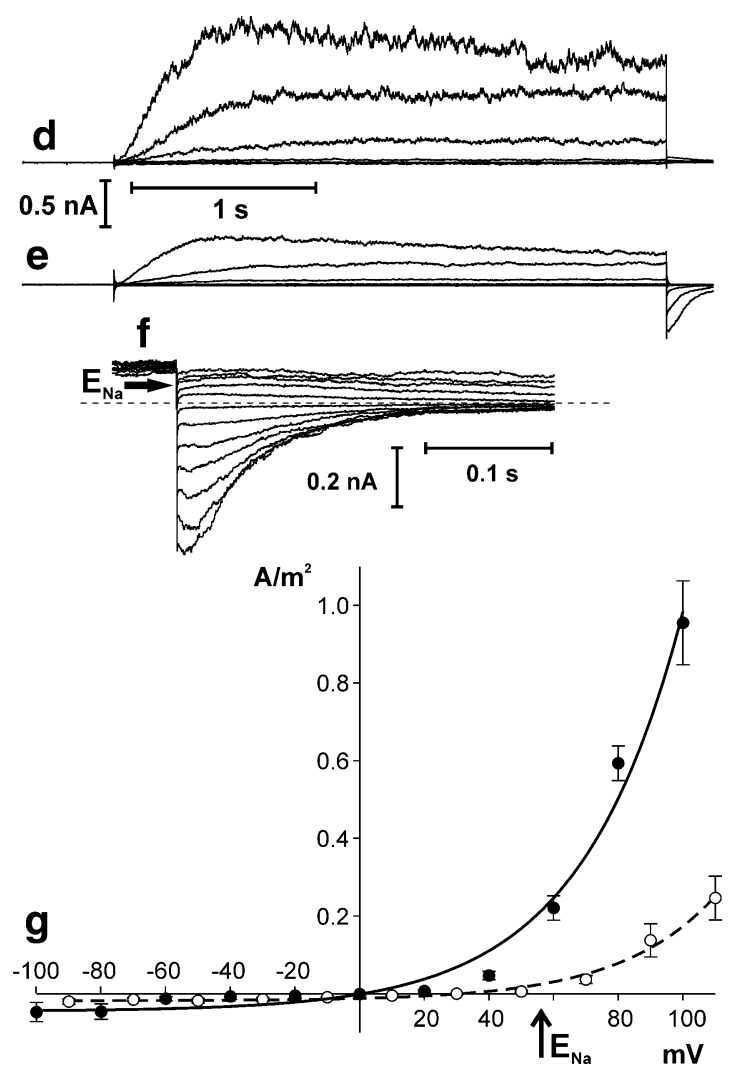

and $100 \mathrm{mM} \mathrm{NaCl}, 2 \mathrm{mM} \mathrm{CaCl}_{2}, 15 \mathrm{mM}$ MES/Tris, pH 5.8 in the pipette. f Tail currents recorded in the same conditions as in e. Holding voltage $(90 \mathrm{mV})$ lasted $2 \mathrm{~s}$ and then test voltages from -30 to $80 \mathrm{mV}$ with $10 \mathrm{mV}$ steps were applied. Dashed line indicates zero current. Horizontal arrow points to the reversal potential. g J-V curves obtained in the same conditions as in $\mathbf{d}$ (solid line and closed circles, $n=4$ ) and e (dashed lines and open circles, $n=4$ ), respectively ( $n$ denotes different vacuoles). Whole-vacuole recordings were obtained by application of $0.5 \mathrm{~s}$ holding voltage $(0 \mathrm{mV}$ for $\mathbf{a}, \mathbf{d}$, $1 \mathrm{mV}$ for $\mathbf{b}$ and $10 \mathrm{mV}$ for $\mathbf{e}$ ), then $3 \mathrm{~s}$ test voltages with $20 \mathrm{mV}$ steps (from 100 to $-100 \mathrm{mV}$ for $\mathbf{a}, \mathbf{d}$, from 101 to $-99 \mathrm{mV}$ for $\mathbf{b}$ and from 110 to $-90 \mathrm{mV}$ for $\mathbf{e})$, and $0.3 \mathrm{~s}$ pulse $(0 \mathrm{mV}$ for $\mathbf{a}, \mathbf{d}, 1 \mathrm{mV}$ for $\mathbf{b}$ and $10 \mathrm{mV}$ for e) after test voltage

symmetrical $\mathrm{K}^{+}$concentration, and at $+80 \mathrm{mV}$ it reached $30.9 \pm 0.5 \mathrm{pS}(n=6)$.

Application of $\mathrm{Na}^{+}$on the cytoplasmic side of the membrane and $\mathrm{K}^{+}$on the vacuole lumen allowed separation of two types of currents (Fig. 3a, b). Under such conditions, SV channels could be active at both positive and negative voltages, whereas $\mathrm{K}^{+}$-selective channels only at negative voltages. The I-V curves (Fig. 3b) show $\mathrm{Na}^{+}$ currents flowing through $\mathrm{SV}$ channels (solid regression line) and $\mathrm{K}^{+}$currents (dashed regression line) flowing through $\mathrm{K}^{+}$-selective channels. The decrease in $\left[\mathrm{Ca}^{2+}\right]_{\text {cyt }}$ to $0.1 \mu \mathrm{M}$ caused a decrease in the open probability of the $\mathrm{SV}$ channels but not of the $\mathrm{K}^{+}$-selective channels (Fig. 3c, d). The results indicate that the $\mathrm{K}^{+}$-selective, rather than $\mathrm{SV}$ channels, require lower $\left[\mathrm{Ca}^{2+}\right]_{\text {cyt }}$ to be active. 


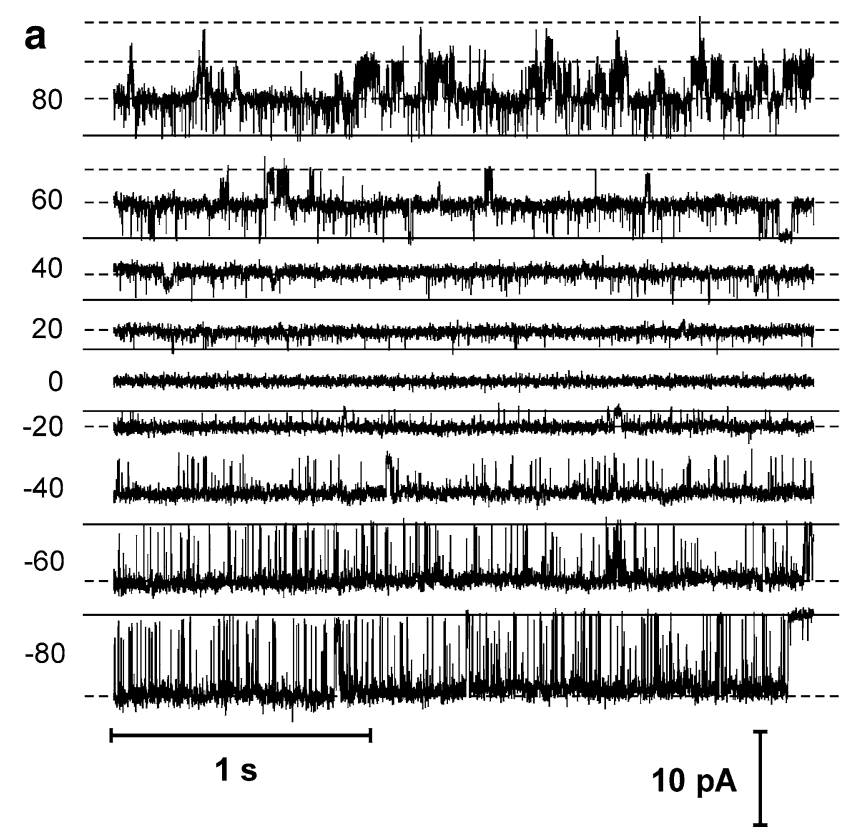

Fig. 2 Single channel activity recorded in Physcomitrella patens vacuolar patches when the current was carried by $\mathrm{K}^{+}$(a) and $\mathrm{Na}^{+}$(b). a The cytoplasm-out currents recorded at $100 \mathrm{mM} \mathrm{KCl}, 2 \mathrm{mM} \mathrm{CaCl}_{2}$, $15 \mathrm{mM}$ HEPES/Tris, $\mathrm{pH} 7$ in the medium and $100 \mathrm{mM} \mathrm{KCl}, 2 \mathrm{mM}$

Dependence of SV channel activity on the cytoplasmic $\mathrm{Ca}^{2+}$ concentration was further examined using $10 \mu \mathrm{M}$ $\left[\mathrm{Ca}^{2+}\right]_{\text {cyt }}$ (Fig. 4a, b), and $1 \mu \mathrm{M}\left[\mathrm{Ca}^{2+}\right]_{\text {cyt }}$ (Fig. 4c, d) at a high vacuolar $\mathrm{Ca}^{2+}$ concentration $(2 \mathrm{mM})$. The histograms based on the recordings carried out at different $\left[\mathrm{Ca}^{2+}\right]_{\mathrm{cyt}}$ show that the decrease in $\left[\mathrm{Ca}^{2+}\right]_{\text {cyt }}$ caused a decrease in the open probability but did not affect conductance. Not only the cytoplasmic, but also vacuolar $\mathrm{Ca}^{2+}$ concentration $\left[\mathrm{Ca}^{2+}\right]_{\mathrm{vac}}$ affected SV channel activity. While $\left[\mathrm{Ca}^{2+}\right]_{\mathrm{cyt}}$ activated the SV channels, $\left[\mathrm{Ca}^{2+}\right]_{\mathrm{vac}}$ inhibited their activity. Measurements carried out at $\left[\mathrm{Ca}^{2+}\right]_{\mathrm{vac}}$ reduced to zero and $1 \mu \mathrm{M}\left[\mathrm{Ca}^{2+}\right]_{\text {cyt }}$ (Fig. 4e, f) showed that there was high activity of SV channels even at $+36 \mathrm{mV}$. The inhibitory effect of $\left[\mathrm{Ca}^{2+}\right]_{\text {vac }}$ on SV channel activity is a common phenomenon in vascular plants. It was observed, among others, in Beta vulgaris (Pottosin et al. 2004) and A. thaliana (Beyhl et al. 2009).

Apart from the $\mathrm{SV}$ channels, also the $\mathrm{K}^{+}$-selective channels proved to be calcium dependent (Fig. 5a-d). In comparison to the $\mathrm{SV}$ channels, the $\mathrm{K}^{+}$-selective channels were active even in the absence of $\mathrm{Ca}^{2+}$ on both sides of the tonoplast (Fig. 5c, d). However, the open probability of the channels in the absence of $\mathrm{Ca}^{2+}$ on the cytoplasmic side was low and amounted to $0.302 \pm 0.105(n=4)$. At low physiological $\left[\mathrm{Ca}^{2+}\right]_{\text {cyt }}$ equal $0.1 \mu \mathrm{M}$, the $\mathrm{K}^{+}$-selective channels exhibited high activity (Fig. 5a, b). The open probability equalled $0.674 \pm 0.042(n=4)$.

Since SV channels in almost all plant species tested so far are permeable to both mono- and divalent cations, it

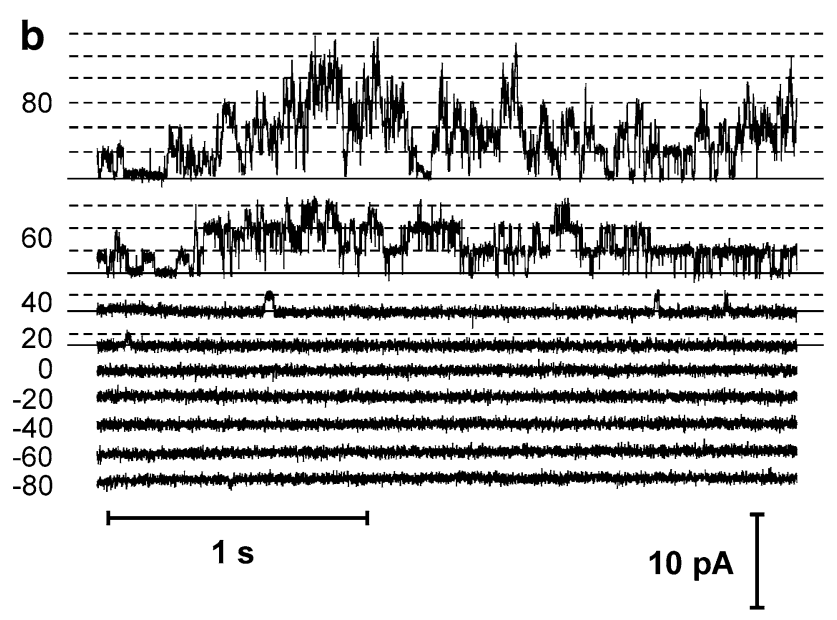

$\mathrm{CaCl}_{2}, 15 \mathrm{mM}$ MES/Tris, $\mathrm{pH} 5.8$ in the pipette. $\mathbf{b}$ The cytoplasm-out currents recorded at $100 \mathrm{mM} \mathrm{NaCl}, 2 \mathrm{mM} \mathrm{CaCl} 2,15 \mathrm{mM}$ HEPES/ Tris, pH 7 in the medium and $100 \mathrm{mM} \mathrm{NaCl}, 2 \mathrm{mM} \mathrm{CaCl}_{2}, 15 \mathrm{mM}$ MES/Tris, pH 5.8 in the pipette

was important to record whole vacuole currents in the presence of $\mathrm{Ca}^{2+}$ as the only permeable cation. Whole vacuole recordings in the $\mathrm{Ca}^{2+}$ gradient promoting $\mathrm{Ca}^{2+}$ efflux from the vacuole showed typical SV currents (Fig. 6a). The reversal potential obtained from relaxation currents (Fig. 6b) and from steady state currents (Fig. 6c) was close to $E_{\mathrm{Ca}}$. The density of the currents was very low (Fig. 6c) and no significant current appeared at negative voltages, indicating negligible $\mathrm{Ca}^{2+}$ flow from the vacuole to the cytoplasm. Figure 6 presents also the results of SV channel activity when $\mathrm{Mg}^{2+}$, another divalent cation, was the only permeable ion. Permeability of the channels to $\mathrm{Mg}^{2+}$ was confirmed by the reversal potential located close to $E_{\mathrm{Mg}}$ (Fig. 6e, f). The whole-vacuole currents (Fig. 6d) and current densities (Fig. 6f) show that $\mathrm{Mg}^{2+}$, likewise $\mathrm{Ca}^{2+}$, flew through the tonoplast mostly in one directionfrom the cytoplasm to the vacuole.

\section{Discussion}

Potassium is the main ion present in the vacuole. This ion can flow through the tonoplast by different types of ion channels (Allen and Sanders 1997; Pottosin et al. 2003; Pottosin and Schönknecht 2007; Hedrich and Marten 2011; Hedrich 2012). Among them is the SV channel, whose activity has been recorded in the tonoplast of all higher plants tested (Pottosin et al. 1997), but not in Charophyta algae (Laver and Walker 1991; Linz and Köhler 1994). 

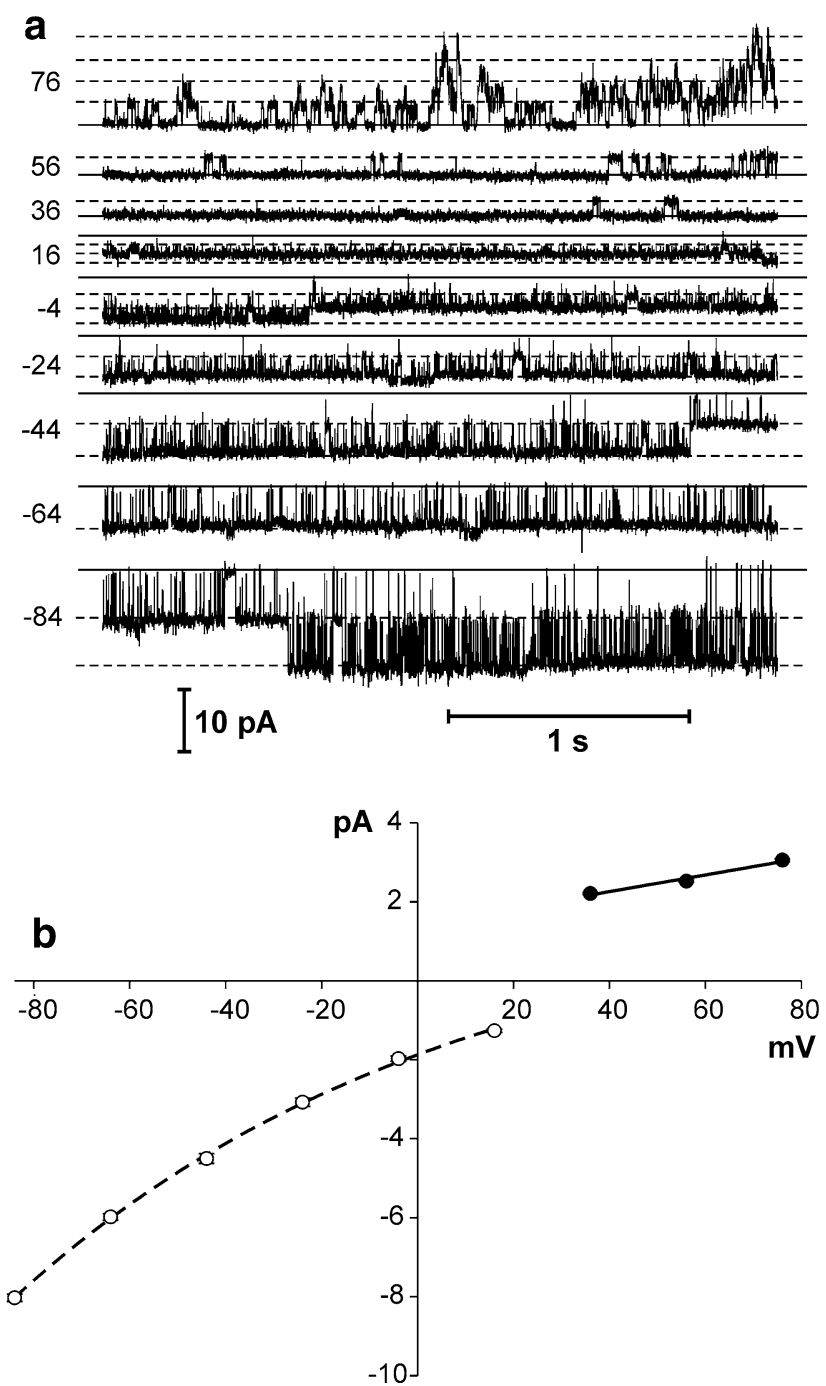

Fig. 3 Simultaneous activity of two types of channels in Physcomitrella patens vacuolar patches. Recordings obtained when the currents were carried by $\mathrm{Na}^{+}$(positive currents-SV type channels) and $\mathrm{K}^{+}$ (negative currents- $\mathrm{K}^{+}$-selective channels). a The cytoplasm-out currents recorded at $100 \mathrm{mM} \mathrm{NaCl}, 10 \mu \mathrm{M} \mathrm{CaCl}_{2}, 15 \mathrm{mM}$ HEPES/ Tris, $\mathrm{pH} 7$ in the medium and $100 \mathrm{mM} \mathrm{KCl}, 2 \mathrm{mM} \mathrm{CaCl}_{2}, 15 \mathrm{mM}$ MES/Tris, pH 5.8 in the pipette. $\mathbf{b} \mathrm{I}-\mathrm{V}$ curves obtained in the same

Activity of these ion channels has also been recorded in the liverwort Conocephalum conicum phylogenetically related to Physcomitrella patens (Trebacz and Schönknecht 2000). Recent experiments have demonstrated the existence of SV channels in Physcomitrella patens. The TPC1 ortholog from Physcomitrella expressed in Arabidopsis gave typical SV currents (Dadacz-Narloch et al. 2011).

In the vacuoles isolated from Physcomitrella (in a native system), we recorded complex currents in conditions favourable for activation of SV channels. The whole-vacuole currents in the symmetrical $\mathrm{KCl}$ concentration differed in kinetics depending on the tonoplast polarisation. At positive voltages, currents with slow kinetics of
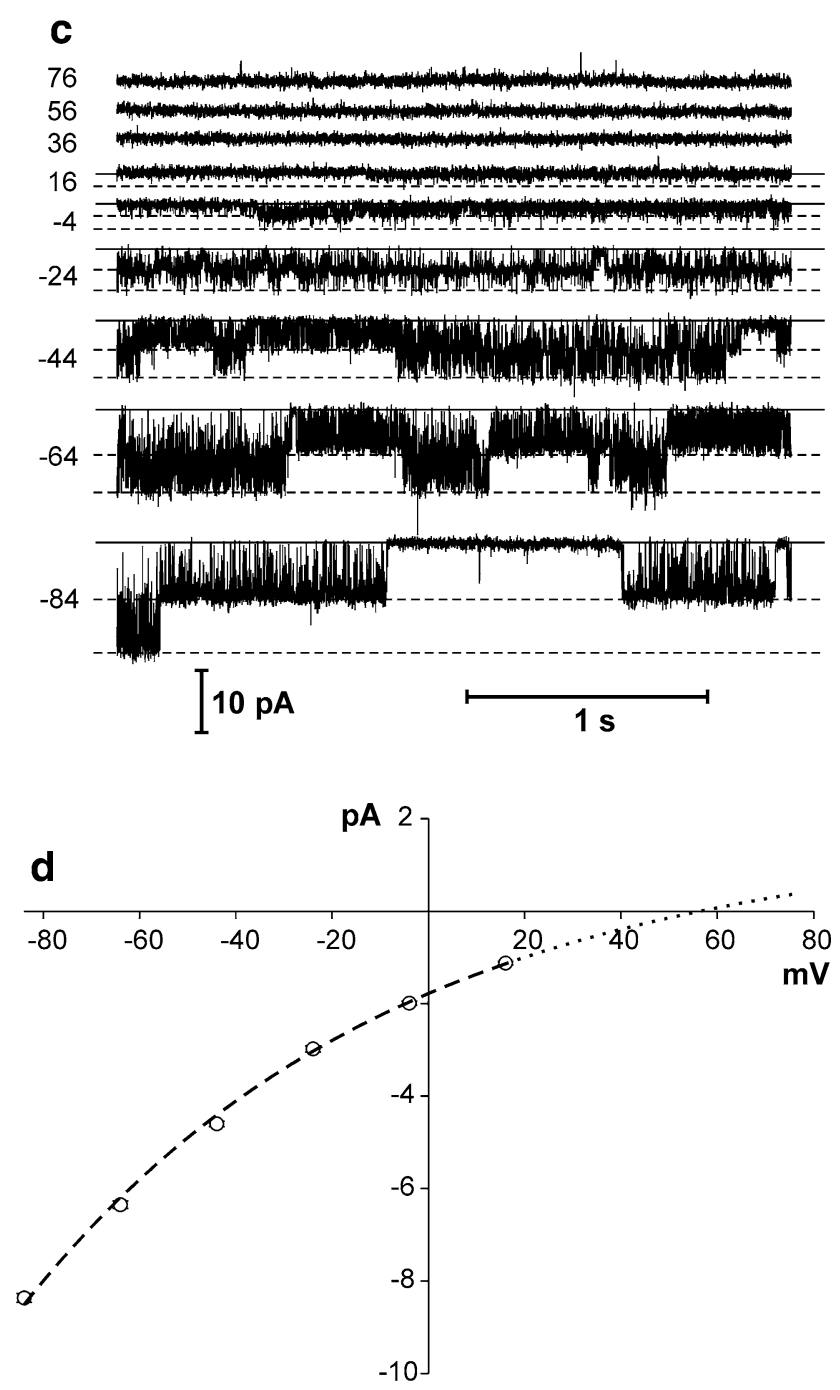

conditions as in a $(n=5)$. Solid line and closed circles denote currents carried by SV type channels and dashed line and open circles- $\mathrm{K}^{+}$-selective channels. c Cytoplasm-out currents recorded at $100 \mathrm{mM} \mathrm{NaCl}, 0.1 \mu \mathrm{M} \mathrm{CaCl}_{2}, 15 \mathrm{mM}$ HEPES/Tris, $\mathrm{pH} 7$ in the medium and $100 \mathrm{mM} \mathrm{KCl}, 2 \mathrm{mM}$ EGTA, $15 \mathrm{mM}$ MES/Tris, pH 5.8 in the pipette. d I-V curve obtained in the same conditions as in c $(n=7)$ ( $n$ denotes different vacuoles $)$

activation were recorded. At negative and partially at positive voltages, currents passing through the Physcomitrella tonoplast exhibited fast activation and values exceeding by orders of magnitude the SV currents at these voltages (Fig. 1a). Occasionally, clear SV currents were recorded in these conditions with practically no currents at negative voltages (data not shown). Thus, it can be concluded that in most cases we registered currents passing through two different types of ion channels. These could be two different $\mathrm{K}^{+}$-conducting channels including $\mathrm{SV}$, or $\mathrm{SV}$ and an anion channel conducting $\mathrm{Cl}^{-}$. A similar result was registered in vacuoles of Conocephalum conicum where at a high $\left[\mathrm{Ca}^{2+}\right]_{\text {cyt }}$ concentration SV and anion channels were 

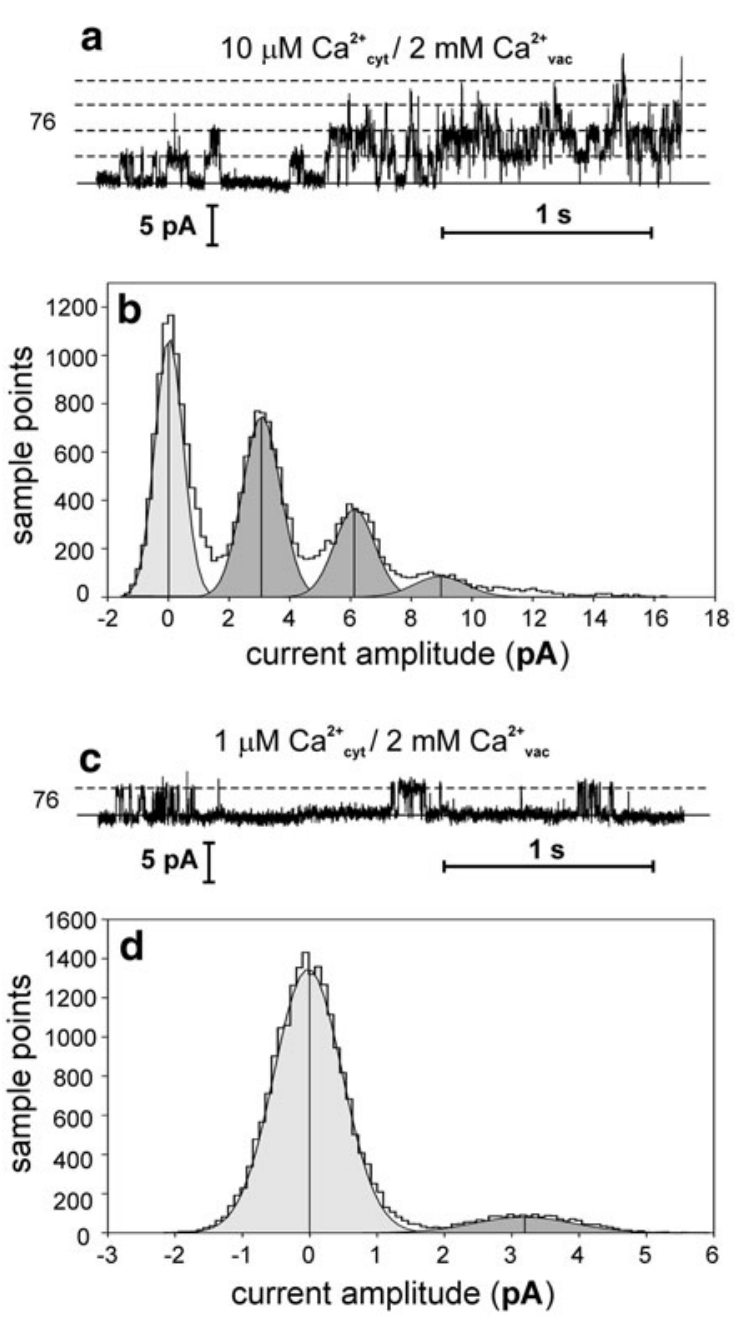

Fig. 4 Influence of cytoplasmic and vacuolar calcium on the SV type channel activity. The records were obtained in the cytoplasm-out configuration at $76 \mathrm{mV}(\mathbf{a}, \mathbf{c})$ and $36 \mathrm{mV}$ (e). a Channel activity recorded at $10 \mu \mathrm{M} \mathrm{CaCl}_{2}, 100 \mathrm{mM} \mathrm{NaCl}, 15 \mathrm{mM}$ HEPES/Tris, $\mathrm{pH} 7$ in the medium and $2 \mathrm{mM} \mathrm{CaCl}_{2}, 100 \mathrm{mM} \mathrm{KCl}, 15 \mathrm{mM} \mathrm{MES} /$ Tris, $\mathrm{pH}$ 5.8 in the pipette. $\mathbf{b}$ Histogram based on four records as in a. $\mathbf{c}$ Channel activity recorded at $1 \mu \mathrm{M} \mathrm{CaCl}_{2}, 100 \mathrm{mM} \mathrm{NaCl}, 15 \mathrm{mM}$ HEPES/

activated at positive and negative voltages, respectively, both nearly perfectly rectifying-promoting $\mathrm{K}^{+}$and $\mathrm{Cl}^{-}$ flux from the cytosol to the vacuole (Trebacz et al. 2007). However, application of the $\mathrm{KCl}$ gradient favouring $\mathrm{K}^{+}$ and $\mathrm{Cl}^{-}$flux from the vacuole to the cytosol should reduce both currents. This was not the case at negative voltages (Fig. 1b, c), which makes activation of anion channels questionable. Moreover, the reversal potential of wholevacuole currents determined upon the $\mathrm{KCl}$ gradient being close to $E_{\mathrm{K}}$ practically eliminates anion channels from consideration.

The open probability of SV channels in different plant species is much higher at positive than at negative voltages (in the symmetrical $\mathrm{KCl}$ concentration). The high and nearly equal open probability at positive and negative
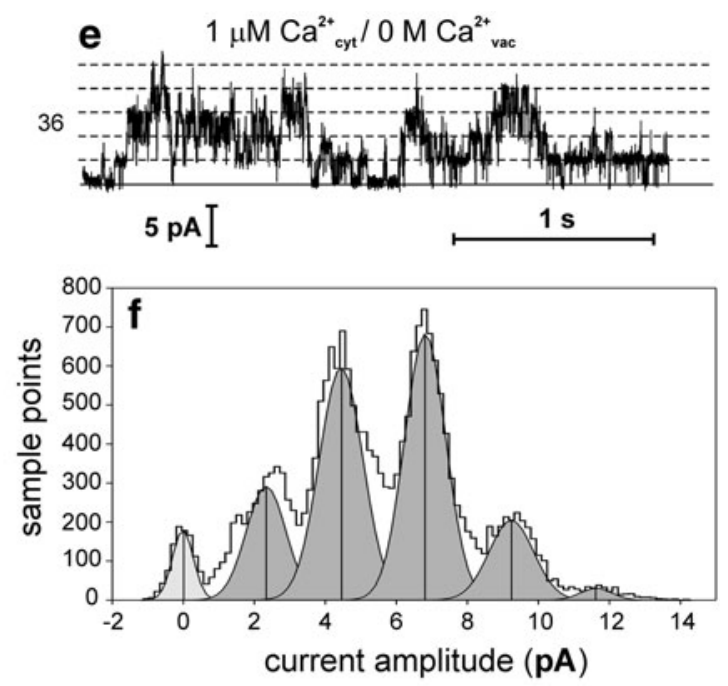

Tris, $\mathrm{pH} 7$ in the medium and $2 \mathrm{mM} \mathrm{CaCl}_{2}, 100 \mathrm{mM} \mathrm{KCl}, 15 \mathrm{mM}$ $\mathrm{MES} /$ Tris, pH 5.8 in the pipette. $\mathbf{d}$ Histogram based on four records as in c. e Channel activity recorded at $1 \mu \mathrm{M} \mathrm{CaCl}_{2}, 100 \mathrm{mM} \mathrm{NaCl}$, $15 \mathrm{mM}$ HEPES/Tris, $\mathrm{pH} 7$ in the medium and $2 \mathrm{mM}$ EGTA, $100 \mathrm{mM}$ $\mathrm{KCl}, 15 \mathrm{mM}$ MES/Tris, pH 5.8 in the pipette. f Histogram based on four records as in $\mathbf{e}$

voltages recorded in the symmetrical concentration of $100 \mathrm{mM} \mathrm{KCl}$ and $2 \mathrm{mM} \mathrm{CaCl}{ }_{2}\left(P_{\mathrm{o}}=0.961 \pm 0.014\right.$ at $+80 \mathrm{mV}$ and $P_{\mathrm{o}}=0.946 \pm 0.005$ at $-80 \mathrm{mV}$ ) (Fig. 2a) indicates that at negative voltages activity of channels different from SV is recorded. After blockage of negative but not positive currents by $\mathrm{Na}^{+}$, it was almost clear that apart from cation-selective SV channels active mostly at positive voltages, channels that distinguish $\mathrm{K}^{+}$over $\mathrm{Na}^{+}$ are active. Existence of two different channels possessing different selectivity was also confirmed using $\mathrm{Na}^{+}$in the cytoplasm and $\mathrm{K}^{+}$in the vacuolar lumen as main permeable ions (Fig. 3).

Measurements with different $\left[\mathrm{Ca}^{2+}\right]_{\text {cyt }}$ showed differences in the calcium dependence of $\mathrm{SV}$ and $\mathrm{K}^{+}$-selective channels (Figs. 4, 5). Dependence of vacuolar cation 

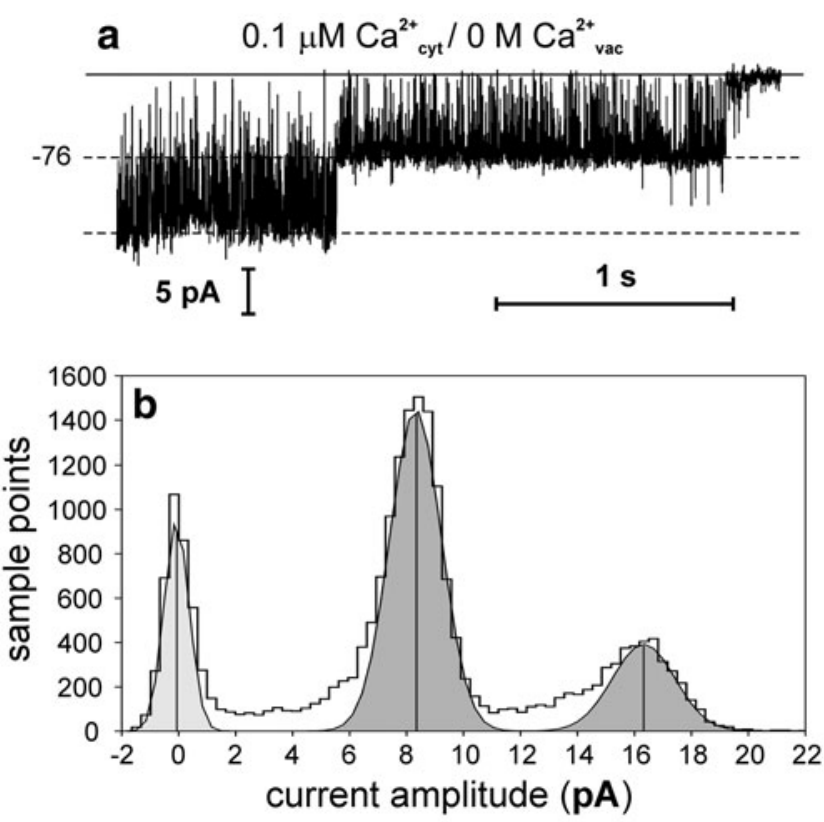

Fig. 5 Influence of cytoplasmic calcium on the $\mathrm{K}^{+}$-selective channel activity. The records were obtained in the cytoplasm-out configuration at $-76 \mathrm{mV}$. a Channel activity recorded at $0.1 \mu \mathrm{M} \mathrm{CaCl}_{2}$, $100 \mathrm{mM} \mathrm{NaCl}, 15 \mathrm{mM}$ HEPES/Tris, $\mathrm{pH} 7$ in the medium and $2 \mathrm{mM}$ EGTA, $100 \mathrm{mM} \mathrm{KCl}, 15 \mathrm{mM}$ MES/Tris, pH 5.8 in the pipette.

channel activity on $\left[\mathrm{Ca}^{2+}\right]_{\text {cyt }}$ occurs for example in Vicia $f a b a$, where changes in $\left[\mathrm{Ca}^{2+}\right]_{\mathrm{cyt}}$ caused changes in activation of three different cation-permeable channels: SV, VK, and FV (Allen and Sanders 1996). $\mathrm{Ca}^{2+}$-dependence could be a good criterion of identifying channel types operating in the Physcomitrella vacuole. In addition to SV channels, activation of two other channels in Physcomitrella needs consideration, i.e. FV and VK channels. FV channels are relatively non-selective cation-permeable transporters (Brüggemann et al. 1999) which require a $\left[\mathrm{Ca}^{2+}\right]_{\text {cyt }}$ level of approx. $10^{-7} \mathrm{M}$ for activation, which is much lower than in the case of SV channels. FV channels in vascular plants exhibit rectification (Tikhonova et al. 1997), which was not the case in Physcomitrella (Figs. 1a, c, 2a). Another feature that allowed us to exclude FV channels from consideration was impermeability of the Physcomitrella channels to $\mathrm{Na}^{+}$. It is much more probable that we recorded currents passing through VK channels which are highly $\mathrm{K}^{+}$-selective and do not possess rectification abilities (Isayenkov et al. 2010).

The vacuolar membrane of Physcomitrella is permeable not only to $\mathrm{K}^{+}$but also to divalent cations. The kinetics of the whole-vacuole recordings: time-dependent activation and outward rectification point to SV channels (Fig. 6). In spite of using a gradient favouring $\mathrm{Ca}^{2+}$ release from the vacuole, only outward currents were registered (Fig. 6a, c). This confirms the recently formulated doubts concerning the role of SV channels in calcium signalling (Ranf et al.
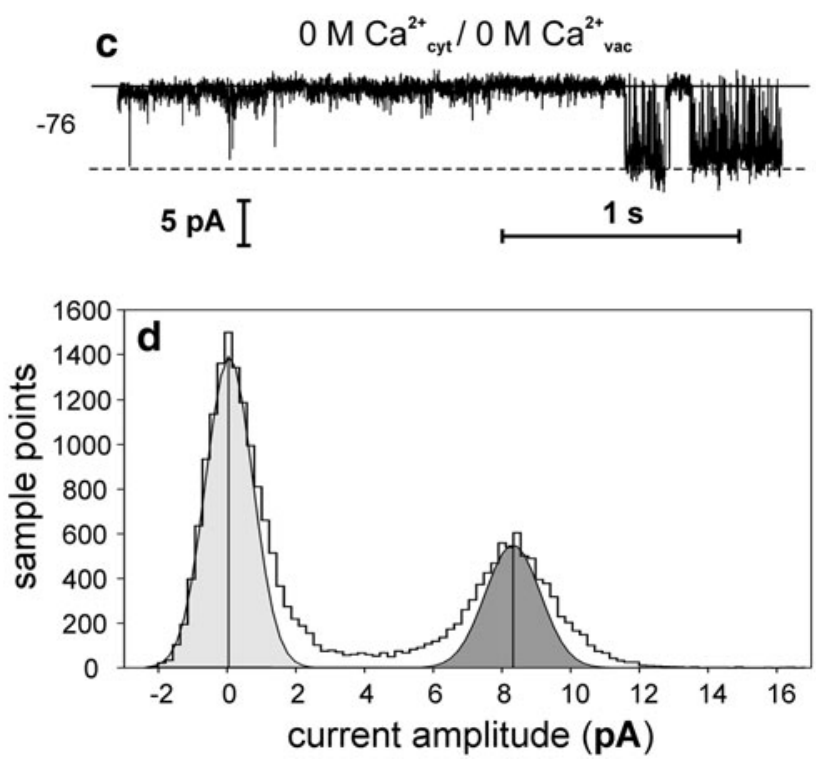

b Histogram based on four records as in a. c Channel activity recorded at $2 \mathrm{mM}$ EGTA, $100 \mathrm{mM} \mathrm{NaCl}, 15 \mathrm{mM}$ HEPES/Tris, $\mathrm{pH} 7$ in the medium and $2 \mathrm{mM}$ EGTA, $100 \mathrm{mM} \mathrm{KCl}, 15 \mathrm{mM} \mathrm{MES/Tris,}$ $\mathrm{pH} 5.8$ in the pipette. d Histogram based on four records as in $\mathbf{c}$

2008). SV currents were also recorded when $\mathrm{Mg}^{2+}$ was the only cation in the medium and in the pipette (Fig. 6d, f). Again, the currents exhibited strong rectification and in the gradient promoting $\mathrm{Mg}^{2+}$ efflux to the cytosol no negative currents were registered. Note that in this case $\mathrm{Ca}^{2+}$ was not added to the bath and pipette solutions. Given that the residual $\mathrm{Ca}^{2+}$ content in the $\mathrm{MgCl}_{2}$ solution (in the absence of EGTA) is less than $1 \mu \mathrm{M}$, it was approx. at the threshold of $\mathrm{SV}$ activation (Fig. 4e). In addition, $\mathrm{Mg}^{2+}$ on the cytoplasmic side lowers the threshold of $\mathrm{SV}$ activation by $\mathrm{Ca}^{2+}$ and shifts the activation potential to more physiological (negative) values (Pei et al. 1999; Carpaneto et al. 2001).

Knowledge about the SV structure and structure-function relations greatly increased after identification of the SV channel protein (TPC1) (Peiter et al. 2005). TPC1 is a two-pore channel possessing two $\mathrm{Ca}^{2+}$ binding EF-hand motifs (Isayenkov et al. 2010). It was recently demonstrated that in A. thaliana the two EF-hands contribute largely to $\mathrm{Ca}^{2+}$-dependent $\mathrm{SV}$ channel activation. A crucial role in $\mathrm{Ca}^{2+}$ regulation was attributed to the EF-hand located near the 7th transmembrane loop (Schulze et al. 2011). The recognised genome of Physcomitrella provides an opportunity to find genes encoding TPC1. Thanks to blast research, we could determine the degree of similarity between TPC1 in Physcomitrella and another model organism-A. thaliana.

We checked the similarity of the TPC1 channel from Physcomitrella and from Arabidopsis in the public 

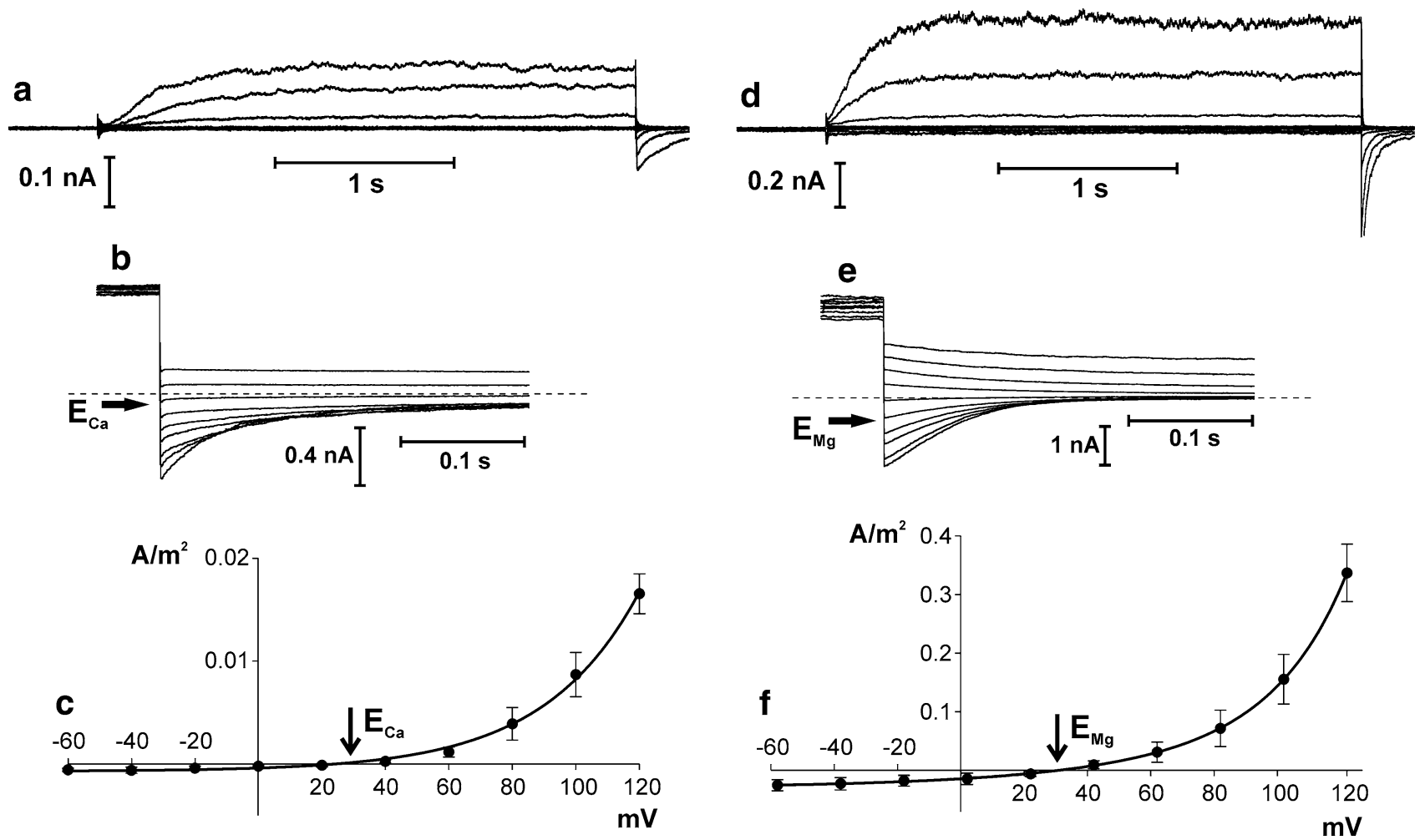

Fig. 6 Ion channel activity recorded in Physcomitrella patens vacuoles when the currents were carried by $\mathrm{Ca}^{2+}(\mathbf{a}-\mathbf{c})$ and $\mathrm{Mg}^{2+}$ (d-f). a Whole-vacuole currents recorded at $1 \mathrm{mM} \mathrm{CaCl}_{2}, 15 \mathrm{mM}$ HEPES/Tris, $\mathrm{pH} 7$ in the medium and $10 \mathrm{mM} \mathrm{CaCl}_{2}, 15 \mathrm{mM} \mathrm{MES/}$ Tris, $\mathrm{pH} 5.8$ in the pipette. b Tail currents recorded at $5 \mathrm{mM} \mathrm{CaCl}_{2}$, $15 \mathrm{mM}$ HEPES/Tris, pH 7 in the medium and $50 \mathrm{mM} \mathrm{CaCl}_{2}, 15 \mathrm{mM}$ MES/Tris, pH 5.8 in the pipette. Holding voltage $(100 \mathrm{mV})$ lasted $2 \mathrm{~s}$ and then test voltages from -30 to $50 \mathrm{mV}$ with $10 \mathrm{mV}$ steps were applied. Dashed line indicates zero current. Horizontal arrow points to the reversal potential. $\mathrm{c} \mathrm{J}-\mathrm{V}$ curve obtained in the same conditions as in a (solid line and closed circles, $n=4$ ). d Whole-vacuole currents recorded at $10 \mathrm{mM} \mathrm{MgCl}_{2}, 15 \mathrm{mM}$ HEPES/Tris, $\mathrm{pH} 7$ in the

databases of genes and proteins (http://www.ncbi.nlm.nih. gov/). Encoded by the PpTPCl gene (GenBank accession AB211222), the putative TPC1 channel in Physcomitrella (BAF34917) is built of 752 amino acids and possesses two pore forming domains (amino acids 138-321; 484-684). A Blast (NCBI Blastp) search shows two putative TPC1 channels in Arabidopsis (NP_567258, BAB55460) with an almost identical protein length (733 amino acids) and $52 \%$ sequence identity. Similar protein length (680-749 amino acids) and sequence identity (51-54\%) were exhibited by two-pore channels found in other plant species such as Zea mays (ACG26617), Nicotiana tabacum (Q75VR0), Vitis vinifera (XP_002273215, ACH53197, CBI21853), Brachypodium distachyon (XP_003569558), Triticum aestivum (Q6YLX9), Arabidopsis lyrata (XP_002874860), and Populus trichocarpa (XP_002330633).

Existence of calcium-binding domains in TPC1 from Physcomitrella was checked in the Prosite database of

medium and $100 \mathrm{mM} \mathrm{MgCl}$, $15 \mathrm{mM} \mathrm{MES/Tris,} \mathrm{pH} 5.8$ in the pipette. e Tail currents recorded in the same conditions as in d. Holding voltage $(102 \mathrm{mV})$ lasted $2 \mathrm{~s}$ and then test voltages from -8 to $82 \mathrm{mV}$ with $10 \mathrm{mV}$ steps were applied. Dashed line indicates zero current. Horizontal arrow points to the reversal potential. f J-V curve obtained in the same conditions as in $\mathbf{d}(n=7)$ ( $n$ denotes different vacuoles). Whole-vacuole recordings were obtained by application of $0.5 \mathrm{~s}$ holding voltage ( $20 \mathrm{mV}$ for $\mathbf{a}$, and $22 \mathrm{mV}$ for $\mathbf{d}$ ), then $3 \mathrm{~s}$ test voltages with $20 \mathrm{mV}$ steps (from 120 to $-60 \mathrm{mV}$ for a and from 122 to $-58 \mathrm{mV}$ for $\mathbf{d})$, and $0.3 \mathrm{~s}$ pulse ( $20 \mathrm{mV}$ for $\mathbf{a}$ and $22 \mathrm{mV}$ for d) after test voltage

protein domains (http://prosite.expasy.org/). Calciumbinding domains were not found in the putative TPC1 channel (BAF34917) encoded by the PpTPCl gene, but was found in two other proteins from Physcomitrella (BAF34918, XP_001779439) similar to BAF34917 (64-65\% sequence identity).

In Arabidopsis, the VK channel is coded by the TPKI gene (Gobert et al. 2007). We have found in the NCBI database that Physcomitrella possesses proteins homologous to the product of $T P K 1$, although these proteins are built of fewer amino acids than in Arabidopsis (363 amino acids in Arabidopsis and 291-317 in Physcomitrella). The sequence identity of the putative TPK1 proteins in Physcomitrella and Arabidopsis is also low and does not exceed $53 \%$. Again, like in the case of SV/TPC1, TPK1 in Arabidopsis possesses two EF-hand domains. This explains the requirement of submicromolar $\left[\mathrm{Ca}^{2+}\right]_{\text {cyt }}$ for $\mathrm{VK}$ activation (Pottosin et al. 2003). In Physcomitrella, according to the 
Prosite database, one of the three putative TPK1 proteins possesses two EF-hand domains and the other two proteins-only one. Differences in the number of the EF-hand domains occur also in Arabidopsis TPK isoforms. For example, no EF-hands are present in AtTPK4 located in the plasma membrane (Becker et al. 2004). It is possible that in Physcomitrella different isoforms of the putative TPK1 are present and these isoforms exhibit different calcium dependence. It is also known that TPK1 in different species differ in respect to calcium dependence. In Arabidopsis, the minimum $\mathrm{Ca}^{2+}$ concentration which activates TPK1 is $\approx 0.5 \mu \mathrm{M}$ (Gobert et al. 2007). In Vicia faba, activation of the VK channel probably coded by TPKI gene requires $\approx 1 \mu \mathrm{M}$ cytoplasmic $\mathrm{Ca}^{2+}$ (Ward and Schroeder 1994). The effect of cytoplasmic $\mathrm{Ca}^{2+}$ was also examined in TPK1 from Nicotiana tabacum, which possesses only one EF-hand domain and is active in the absence of cytoplasmic $\mathrm{Ca}^{2+}$ (Hamamoto et al. 2008). Similar properties were observed in the case of the putative TPK1 channels from Physcomitrella, which were active at nearly $0\left[\mathrm{Ca}^{2+}\right]_{\text {cyt }}$ (Fig. 5).

Our paper presents for the first time a survey of cationpermeable channels in the tonoplast of Physcomitrella patens. Future investigations with application of mutants will provide more detailed characteristics of the channels and help to disclose their physiological role.

Acknowledgments This work was supported by the Ministry of Science and Higher Education Grant No. NN301 464534.

Open Access This article is distributed under the terms of the Creative Commons Attribution License which permits any use, distribution, and reproduction in any medium, provided the original author(s) and the source are credited.

\section{References}

Allen GJ, Sanders D (1996) Control of ionic currents in guard cell vacuoles by cytosolic and luminal calcium. Plant J 10:10551069

Allen GJ, Sanders D (1997) Vacuolar ion channels of higher plants. Adv Bot Res 25:217-252

Allen GJ, Amtmann A, Sanders D (1998) Calcium-dependent and calcium-independent $\mathrm{K}^{+}$mobilization channels in Vicia faba guard cell vacuoles. J Exp Bot 49:305-318

Becker D, Geiger D, Dunkel M, Roller A, Bertl A, Latz A, Carpaneto A, Dietrich P, Roelfsema MRG, Voelker C, Schmidt D, MuellerRoeber B, Czempinski K, Hedrich R (2004) AtTPK4, an Arabidopsis tandem-pore $\mathrm{K}^{+}$channel, poised to control the pollen membrane voltage in a $\mathrm{pH}-$ and $\mathrm{Ca}^{2+}$-dependent manner. Proc Natl Acad Sci USA 101:15621-15626

Bertl A, Blumwald E, Coronado R, Eisenberg R, Findlay G, Gradmann D, Hille B, Kohler K, Kolb HA, Macrobbie E, Meissner G, Miller C, Neher E, Palade P, Pantoja O, Sanders D, Schroeder J, Slayman C, Spanswick R, Walker A, Williams A (1992) Electrical measurements on endomembranes. Science 258:873-874

Beyhl D, Hoertensteiner S, Martinoia E, Farmer EE, Fromm J, Marten I, Hedrich R (2009) The fou 2 mutation in the major vacuolar cation channel TPC1 confers tolerance to inhibitory luminal calcium. Plant J 58:715-723

Brüggemann LI, Pottosin II, Schönknecht G (1999) Selectivity of the fast activating vacuolar cation channel. J Exp Bot $50: 873-876$

Carpaneto A, Cantu AM, Gambale F (2001) Effects of cytoplasmic $\mathrm{Mg}^{2+}$ on slowly activating channels in isolated vacuoles of Beta vulgaris. Planta 213:457-468

Dadacz-Narloch B, Beyhl D, Larisch C, Lopez-Sanjurjo EJ, Reski R, Kuchitsu K, Mueller TD, Becker D, Schönknecht G, Hedrich R (2011) A novel calcium binding site in the slow vacuolar cation channel TPC1 senses luminal calcium levels. Plant Cell 23:2696-2707

Frank W, Ratnadewi D, Reski R (2005) Physcomitrella patens is highly tolerant against drought, salt and osmotic stress. Planta 220:384-394

Gobert A, Isayenkov S, Voelker C, Czempinski K, Maathuis FJM (2007) The two-pore channel TPK1 gene encodes the vacuolar $\mathrm{K}^{+}$conductance and plays a role in $\mathrm{K}^{+}$homeostasis. Proc Natl Acad Sci USA 104:10726-10731

Gutla PVK, Boccaccio A, De Angeli A, Gambale F, Carpaneto A (2012) Modulation of plant TPC channels by polyunsaturated fatty acids. J Exp Bot 63:6187-6197

Hamamoto S, Marui J, Matsuoka K, Higashi K, Igarashi K, Nakagawa T, Kuroda T, Mori Y, Murata Y, Nakanishi Y, Maeshima M, Yabe I, Uozumi N (2008) Characterization of a tobacco TPKtype $\mathrm{K}^{+}$channel as a novel tonoplast $\mathrm{K}^{+}$channel using yeast tonoplasts. J Biol Chem 283:1911-1920

Hedrich R (2012) Ion channels in plants. Physiol Rev 92:1777-1811

Hedrich R, Marten I (2011) TPC1-SV channels gain shape. Mol Plant 4:428-441

Isayenkov S, Isner JC, Maathuis FJM (2010) Vacuolar ion channels: roles in plant nutrition and signalling. FEBS Lett 584:1982-1988

Kroemer K, Reski R, Frank W (2004) Abiotic stress response in the moss Physcomitrella patens: evidence for an evolutionary alteration in signaling pathways in land plants. Plant Cell Rep 22:864-870

Laver DR, Walker NA (1991) Activation by $\mathrm{Ca}^{2+}$ and block by divalent ions of the $\mathrm{K}^{+}$-channel in the membrane of cytoplasmic drops from Chara australis. J Membr Biol 120:131-139

Linz KW, Köhler K (1994) Vacuolar ion currents in the primitive green alga Eremosphera viridis: the electrical properties are suggestive of both the Characeae and higher plants. Protoplasma 179:34-45

Minami A, Nagao M, Ikegami K, Koshiba T, Arakawa K, Fujikawa S, Takezawa D (2005) Cold acclimation in bryophytes: lowtemperature-induced freezing tolerance in Physcomitrella patens is associated with increases in expression levels of stress-related genes but not with increase in level of endogenous abscisic acid. Planta 220:414-423

Pei ZM, Ward JM, Schroeder JI (1999) Magnesium sensitizes slow vacuolar channels to physiological cytosolic calcium and inhibits fast vacuolar channels in fava bean guard cell vacuoles. Plant Physiol 121:977-986

Peiter E, Maathuis FJM, Mills LN, Knight H, Pelloux J, Hetherington AM, Sanders D (2005) The vacuolar $\mathrm{Ca}^{2+}$-activated channel TPC1 regulates germination and stomatal movement. Nature 434:404-408

Pottosin II, Schönknecht G (2007) Vacuolar calcium channels. J Exp Bot 58:1559-1569

Pottosin II, Tikhonova LI, Hedrich R, Schönknecht G (1997) Slowly activating vacuolar channels can not mediate $\mathrm{Ca}^{2+}$-induced $\mathrm{Ca}^{2+}$ release. Plant J 12:1387-1398

Pottosin II, Martinez-Estevez M, Dobrovinskaya OR, Muniz J (2003) Potassium-selective channel in the red beet vacuolar membrane. J Exp Bot 54:663-667 
Pottosin I, Martinez-Estevez M, Dobrovinskaya O, Muniz J, Schönknecht G (2004) Mechanism of luminal $\mathrm{Ca}^{2+}$ and $\mathrm{Mg}^{2+}$ action on the vacuolar slowly activating channels. Planta 219:1057-1070

Ranf S, Wuennenberg P, Lee J, Becker D, Dunkel M, Hedrich R, Scheel D, Dietrich P (2008) Loss of the vacuolar cation channel, AtTPC1, does not impair $\mathrm{Ca}^{2+}$ signals induced by abiotic and biotic stresses. Plant J 53:287-299

Reski R, Abel WO (1985) Induction of budding on chloronemata and caulonemata of the moss, Physcomitrella patens, using isopentenyladenine. Planta 165:354-358

Rienmüller F, Beyhl D, Lautner S, Fromm J, Al-Rasheid KAS, Ache P, Farmer EE, Marten I, Hedrich R (2010) Guard cell-specific calcium sensitivity of high density and activity SV/TPC1 channels. Plant Cell Physiol 51:1548-1554

Saidi Y, Finka A, Muriset M, Bromberg Z, Weiss YG, Maathuis FJM, Goloubinoff P (2009) The heat shock response in moss plants is regulated by specific calcium-permeable channels in the plasma membrane. Plant Cell 21:2829-2843
Schulze C, Sticht H, Meyerhoff P, Dietrich P (2011) Differential contribution of EF-hands to the $\mathrm{Ca}^{2+}$-dependent activation in the plant two-pore channel TPC1. Plant J 68:424-432

Tikhonova LI, Pottosin II, Dietz KJ, Schönknecht G (1997) Fastactivating cation channel in barley mesophyll vacuoles. Inhibition by calcium. Plant J 11:1059-1070

Trebacz K, Schönknecht G (2000) Simple method to isolate vacuoles and protoplasts for patch-clamp experiments. Protoplasma 213:39-45

Trebacz K, Schönknecht G, Dziubinska H, Hanaka A (2007) Characteristics of anion channels in the tonoplast of the liverwort Conocephalum conicum. Plant Cell Physiol 48:1747-1757

Ward JM, Schroeder JI (1994) Calcium-activated $\mathrm{K}^{+}$channels and calcium-induced calcium-release by slow vacuolar ion channels in guard-cell vacuoles implicated in the control of stomatal closure. Plant Cell 6:669-683 